\title{
Fall Prevention: Reduce Your Risk!
}

IFAS EXTENSION

Jennifer Hillan ${ }^{2}$

Some lifestyle factors can affect your risk of falling. Find out how 2 ENAFS much you know about these factors by completing the crossword puzzle!
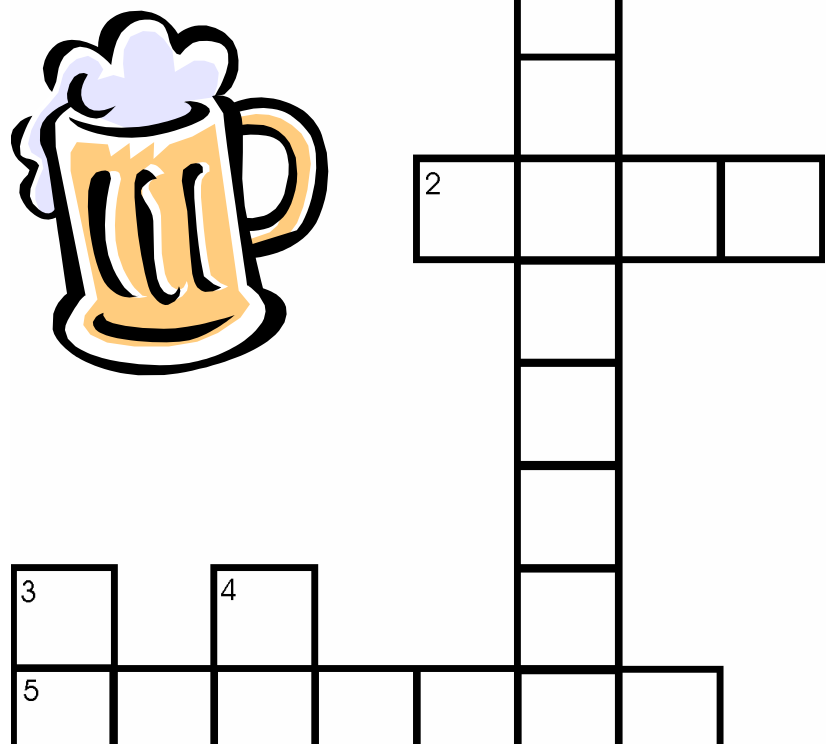

\section{ACROSS}

2. Avoid wearing shoes with heels.

5. Drinking can make you less alert. It can also make you less coordinated.

1. Taking some types of ___ can make you feel dizzy or less alert. Talk to your healthcare provider about yours.

3. One way to stay active is by . All you need is a good pair of shoes!

4. Regular can help improve your strength and balance. It can also improve your health!
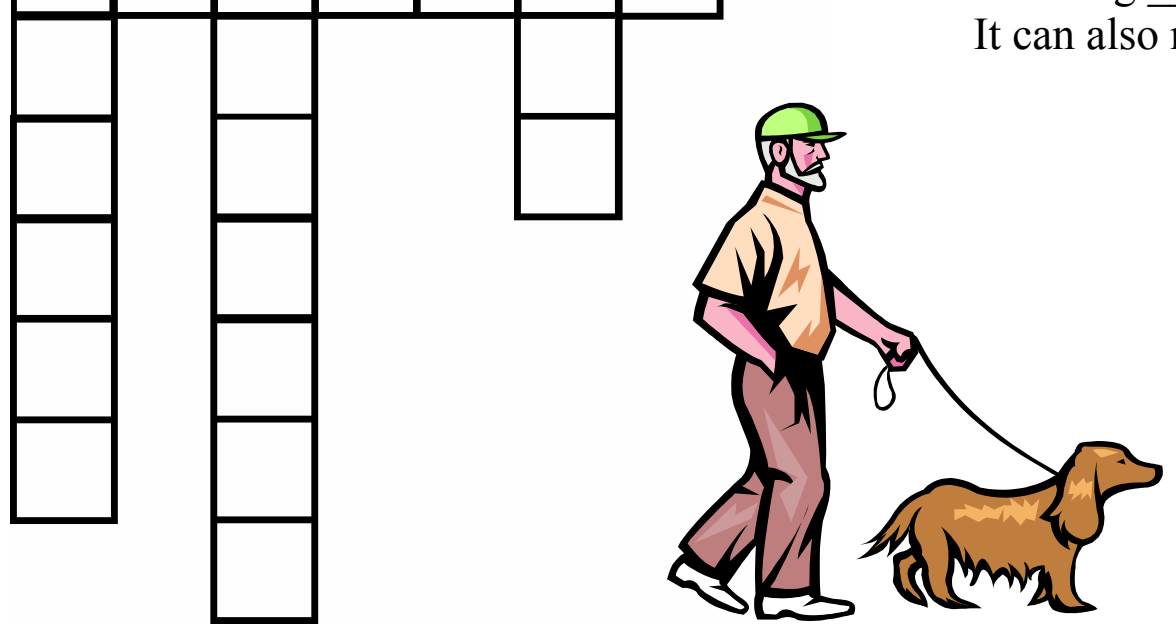

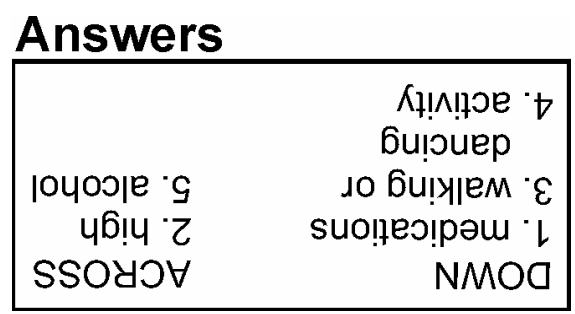

1. This document is FCS2231, one in a series of the Department of Family, Youth and Community Sciences, Florida Cooperative Extension Service, Institute of Food and Agricultural Sciences, University of Florida, Gainesville, FL 32611. Publication date: April 2005. Please visit the EDIS website at http://edis.ifas.ufl.edu

2. Jennifer Hillan, MSH, RD, LD/N, former educator/trainer, Department of Family, Youth and Community Sciences, Institute of Food and Agricultural Sciences, University of Florida, Gainesville, FL 32611. Reviewed by Linda B. Bobroff, PhD, RD, LD/N, Department of Family, Youth and Community Sciences, University of Florida and Carolyn A. Gregov, PhD, Sarasota County Extension Service. 